\title{
Flood Warning and Monitoring System (FWMS) using GSM Technology
}

\author{
Nurzaid Muhd Zain ${ }^{1 *}$, Lidia Shahira Elias², Zulfikri Paidi ${ }^{3}$, Mahfudzah Othman ${ }^{4}$ \\ ${ }_{1,2,3,4}^{4}$ Faculty of Computer and Mathematical Sciences , \\ Universiti Teknologi MARA, Perlis Branch, Arau Campus, 02600 Arau, Perlis \\ Corresponding author: *nurzaid@uitm.edu.my \\ Received Date: 5 September 2020 \\ Accepted Date: 29 September 2020
}

\begin{abstract}
Floods are natural disasters that occur due to climate factors. The impact of floods on property and lives can be too high, resulting in the need to establish a monitoring system. FWMS is a personal flood monitoring system that has the ability to call and send warning via SMS. The warning was sent to not only system users, but also directly to the Fire and Rescue Station as floodwaters rose rapidly to dangerous levels. FWMS is developed using Arduino Uno microcontroller, ultrasonic sensor (HC-SR04) and GSM SIM900A module. Using FWMS, users can apply for flood status in their area in real time via SMS. In FWMS, there are three different levels of flood warning system. The first is the "normal" level, when the situation is normal. The second is the "warning" level, where an SMS will be sent to the users each time a flood is detected. Meanwhile, the third is known as the "danger" level, which will be sent when the depth of the flood that occurs is detected to be higher. For both levels of "warning" and "danger", a loud buzzer will be issued as a warning sound notification to users. Three types of tests were performed on the FWMS to measure its level of performance. These tests were functional tests, prototype system tests, and GSM network performance tests. They were done to ensure that FWMS can be used and function properly as required. The tests have produced positive results and it is potentially to be further enhanced.
\end{abstract}

Keywords: Arduino, early warning system, flood, GSM, SIM900A, monitoring system, ultrasonic sensor

\section{INTRODUCTION}

Flood is one of the major problems that occur in some countries in the world including Malaysia. Since 1971, Malaysia has been affected by flood disaster in many regions (Khalid \& Shafiai, 2015). Flooding is a natural disaster that is caused by climate factors such as rainfall, temperature, wind, and movement of natural conditions on earth. Flood disaster has received 40 to 50 percent of all types of disasters that caused deaths in the world (Diaz, 2004; FitzGerald, Du, Jamal, Clark \& Hou, 2010).

High rate of property destructions happen and many have passed away when the people especially the residents in the flood-prone area and the authorities are all unprepared to face the flash flood (Jacquier, 2015). Residents in the flood-prone area should aware about the status of the flood water level when heavy rainfall or rising of flood water level occur to avoid high destruction of human property percentage. Besides, they should also be informed earlier about the status of current flood water level in their housing area, so that they can move out from the area immediately. These issues could reduce the rate of death and the percentage of property destruction due to flash flood. 
Therefore, a personal Flood Warning and Monitoring System using GSM Technology (FWMS) is developed for any residents who live in the flood-prone areas in order to help them stay alert with the flood water level during monsoon season. This system will be able to call the user whenever the flood water level has reached over dangerous level and transmits accurate warning messages to the user via Short Message Service (SMS). The system measures the real-time flood water level at the floodplain areas and the user has the ability to monitor the flood water level for monitoring purpose. In addition, the user will get a real-time warning message when the flood water is rising rapidly.

This paper discusses on the development of a personal flood monitoring system that can give an alarm call and a warning message to the user and the evaluation of the developed system using ultrasonic sensor, GSM technology and Arduino based on the functionality test and network performance test.

\section{BACKGROUND OF STUDY}

High rate of property destructions happen and many have passed away when the people especially the residents in the flood-prone area and the authorities are all unprepared to face the flash flood (Jacquier, 2015). Residents in the flood-prone area should aware about the status of the flood water level when heavy rainfall or rising of flood water level occur to avoid high destruction of human property percentage. Besides, they should also be informed earlier about the status of current flood water level in their housing area, so that they can move out from the housing area immediately. These issues could reduce the rate of death and the percentage of property destruction due to flash flood. 3

Currently, several flood detection and monitoring systems have been installed in Malaysia in the purpose of monitoring flood water level. Department of Irrigation and Drainage Malaysia states that there are two types of flood monitoring systems used in Malaysia. The systems are the telemetric rain gauge and the water level stations telemetric. About 335 telemetric rain gauges and 208 water level stations telemetric are mounted around Malaysia (Department of Irrigation and Drainage, 2013).

Nonetheless, many flood monitoring systems are not implemented for the residents but to be monitored by the authorities and they will provide the flood status or warning to the residents later. Moreover, the systems are usually mounted near the dams, dikes, river basins and drains (Chan, 2012; Khalid and Shafiai, 2015). The current systems are lack of efficiency in sending information to the authorities and residents in flood-prone area. Some flood monitoring systems may transmit error or false information to them (Cherishma et al., 2017). Consequently, the flood-prone area residents could not get the accurate updates of the flood water level in their housing area and the authorities might be late for rescuing the flood victims. Furthermore, the flood victims should have enough time to move to a safer place, so they need to be notified about the flood water level and be warned much earlier (Priya, Akshaya, Aruna, Julie, \& Ranjani, 2017).

If these problems are not being considered, the rate of flood victims will increase since they could not leave from the housing area when the flood water level is rising rapidly. In addition, a higher rate of property destruction will occur when the flood victims are given a last-minute flood warning message and they might be trapped (Eetha, Ekhar, Aj, \& Ravin, 2017; K, 2012). 


\section{PROJECT SCOPE}

This study is focused on residential area in flood-prone areas which are near to paddy field, river watersheds and drains especially in the Northern Region and East Coast of Malaysia which comprises of Perlis, Kedah, Perak, Penang, Kelantan, Terengganu and Pahang. For this project, the system has been implemented at Beseri and Arau, which are located in Perlis because these two areas are among the most affected area in Perlis (Bernama, 2017).

The flood water level and the time taken of the warning call and the alert message that will be received by the user will be measured. Another measurement is the time taken that the warning/alert buzzer to be functional well when the water level reaches the highest water level which the measurement will be set at certain level. However, alternatives to prevent the flood from entering the house area will not be measured as the system is an early warning and monitoring system. Furthermore, the data that will be collected are the current water level and the current status of the flood. The flood warning and monitoring system device can be installed at the house area such as the gates, walls or even drains. The best place to mount the system is on a lower earth surface area near the house that the flood water would be entered first. However, it depends on the suitable place that the system device can be installed. Then, the reading result will be sent to the user.

\section{METHODOLOGY}

In general, FWMS is divided into six phases which are initiation, planning, development, evaluation, analysis and documentation as shown in Figure 1.

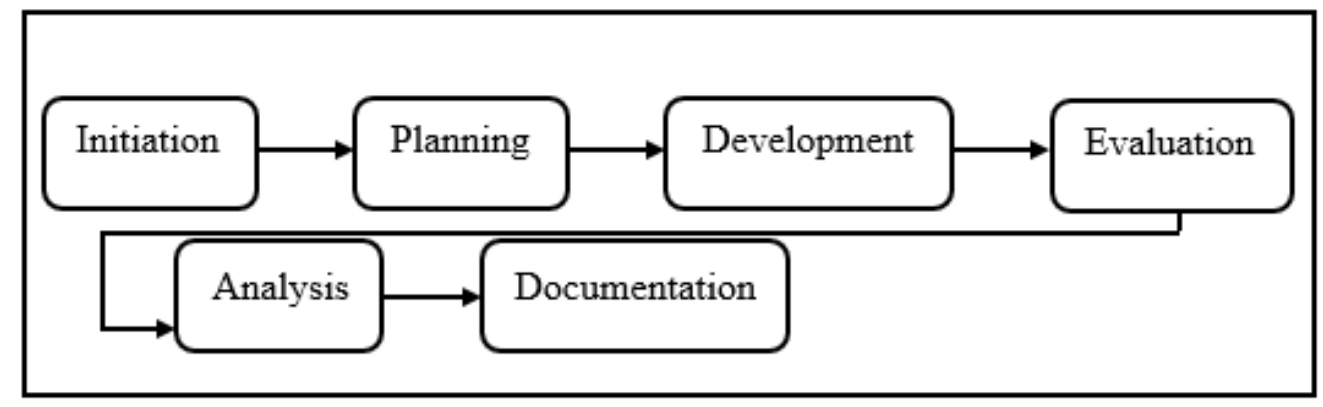

Figure 1: Methodology phases

\section{A. Proposed Architecture}

The system used GSM network via the GSM SIM900A module embedded with the microcontroller. Moreover, the user has two-way communication with the system while Fire and Rescue Department is unidirectional.

The user has the ability to request real-time flood water level, receive warning SMS and also incoming alarm call from the system. The fire and rescue department officers will receive a warning SMS from the system when the flood water level rises over certain critical level. The proposed architecture is shown in Figure 2. 


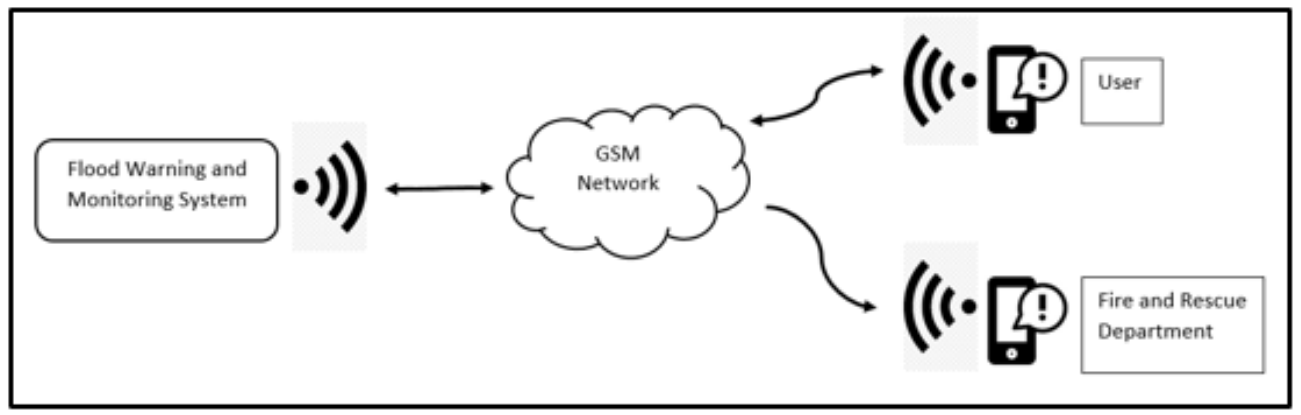

Figure 2: Proposed architecture

\section{B. Prototype Development}

The main hardware components used in this project are Arduino Uno, Ultrasonic Sensor, Liquid Crystal Display (LCD), GSM SIM900A Module and Piezo buzzer alarm. The usage and descriptions of each of the component are described as below:

i. Ultrasonic sensor is one of the essential components that measure the flood water level. This sensor has the ability to measure distances of an object. The sound wave used in ultrasonic sensor calculates the distances.

ii. GSM module is purposely used for data transmissions over the network between the microcontroller and the user's mobile phone. The model of GSM module used in this project is SIM900A. The model is the most suitable model for the project because it is low powered and the price is affordable for the project.

iii. Liquid Crystal Display (LCD) has the ability to display the readings through the LCD screen. For this project, the $16 \times 2$ LCD is used to display the status and the flood water level.

iv. A piezo buzzer is also an essential component for this project for alarming the surrounding when it reaches "Dangerous" and "Warning" flood water level.

v. An Arduino IDE is used in order to code the functions of the project. Arduino IDE is a software to program a microcontroller. It contains a text editor, message area, text console, toolbar and series of menus. IDE stands for Integrated Development Environment. 


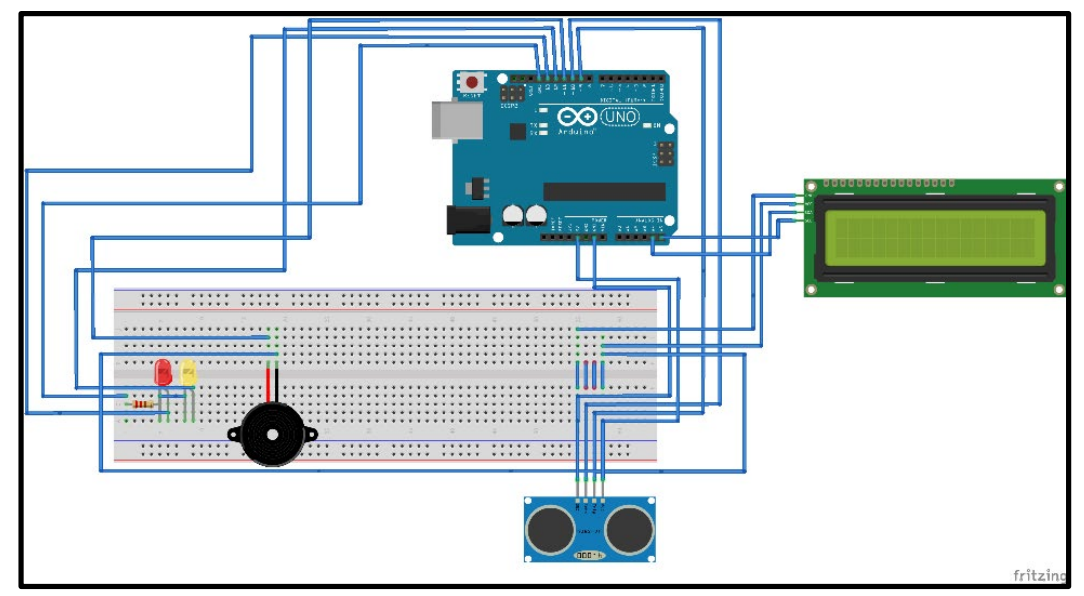

Figure 3: Schematic diagram of FWMS (without GSM module)

Figure 3 shows the schematic diagram of FWMS without the GSM module while Figure 4 shows the schematic diagram of FWMS connected with GSM SIM900A module.

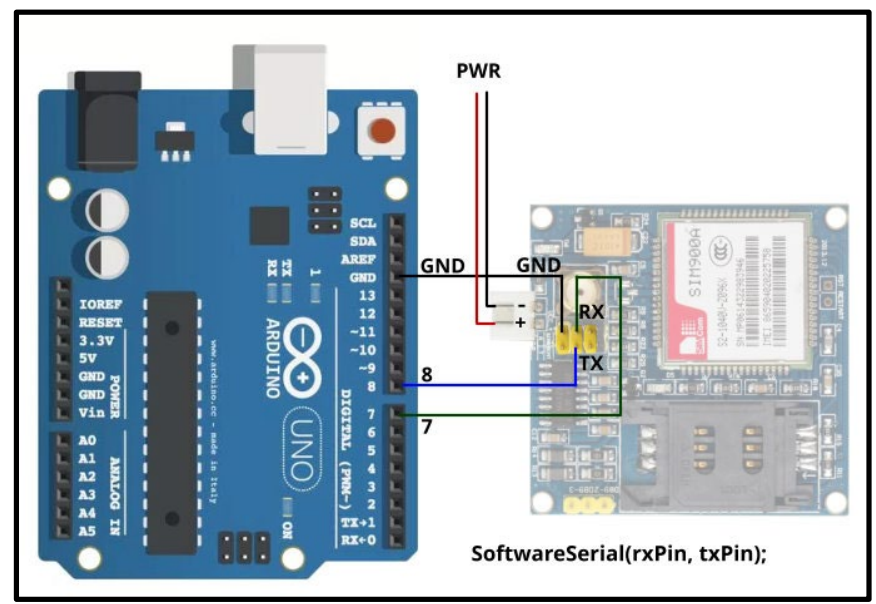

Figure 4: FWMS connected to GSM SIM900A module

A translucent storage box is used as an indication of the flood water level. PVC pipes are cut into equal size of the length and width of the storage box so that it fits. The PVC pipes are act as holder the device box. The cover of the storage box is used for holding and acts as the plate for the device box. A mediumsized plastic box is used to keep the system components as such in Figure 5.

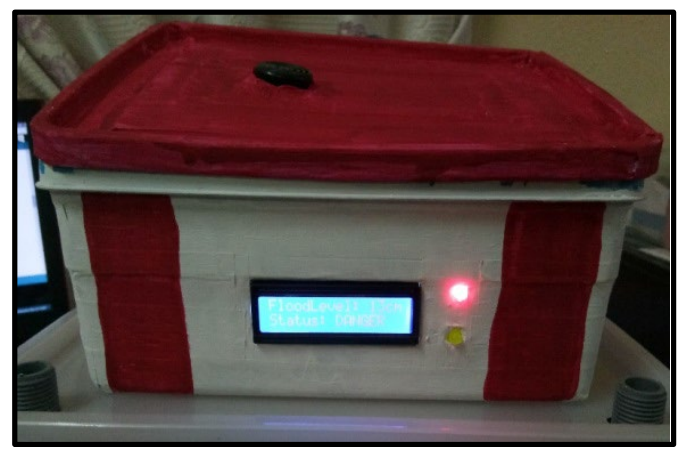

Figure 5: FWMS device box 
This plastic box acts as the essential device box which all the connected components are stored. The FWMS complete prototype is shown in Figure 6.

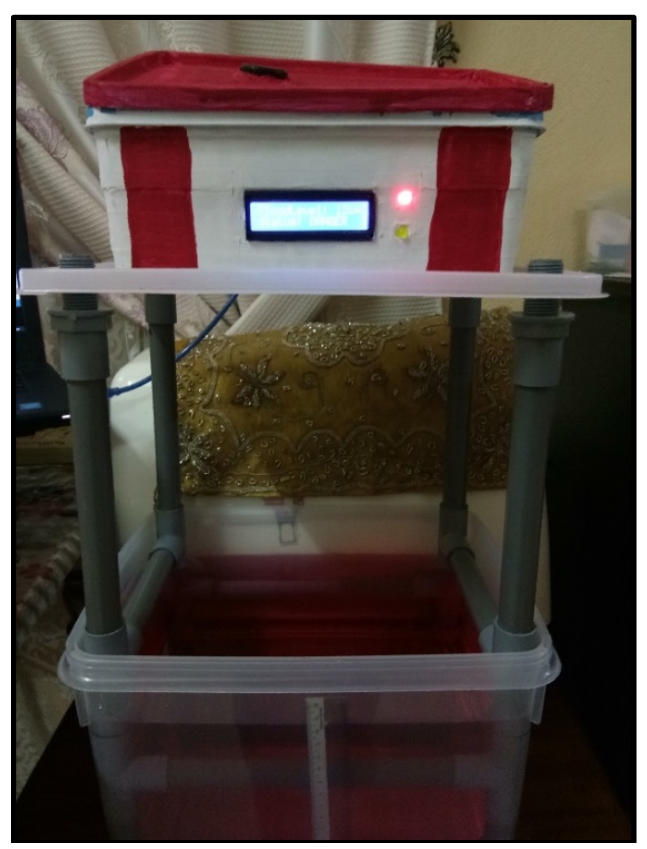

Figure 6: Complete FWMS prototype

\section{TESTING AND EVALUATION}

There are three tests have been conducted for this project. The following are the tests that were performed:

i. Functionality test

ii. Prototype system test

iii. GSM network performance test

\section{i. Functionality test}

There are three stages of flood water level that has been configured. The stages are Normal, Warning and Danger levels. These stages are configured for the efficiency of the developed project. Table 1 shows the result of the FWMS functionality test with three test cases. The expected outcomes are successfully met and this test has been conducted several times for the consistency of the functionalities.

Table 1: Results of the Functionality Test

\begin{tabular}{|c|c|c|c|c|c|c|l|}
\hline \multirow{2}{*}{\begin{tabular}{c}
\multirow{2}{*}{$\begin{array}{c}\text { Flood water } \\
\text { level (cm) }\end{array}$} \\
\cline { 3 - 7 }
\end{tabular}} & $\begin{array}{c}\text { LCD } \\
\text { display } \\
\text { (Status) }\end{array}$ & LED & Buzzer & $\begin{array}{c}\text { GSM } \\
\text { receive/send } \\
\text { SMS }\end{array}$ & $\begin{array}{c}\text { GSM } \\
\text { call }\end{array}$ & Results \\
\hline Case 1: & $0-5$ & NORMAL & OFF & OFF & User & - & Success \\
\hline Case 2: & $6-10$ & WARNING & Yellow & ON & User & - & Success \\
\hline Case 3: & $>10$ & DANGER & Red & ON & $\begin{array}{c}\text { Fire \& } \\
\text { Rescue Dept. }\end{array}$ & User & Success \\
\hline
\end{tabular}

Figure 7 shown below is the warning SMS received by the user whenever Case 2 is detected. In addition, Figure 8 shows the incoming alarm call from FWMS to the user when the flood water level has reached the dangerous level. 


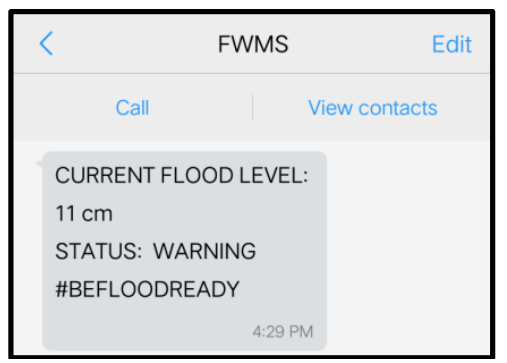

Figure 7: Warning SMS received by the user

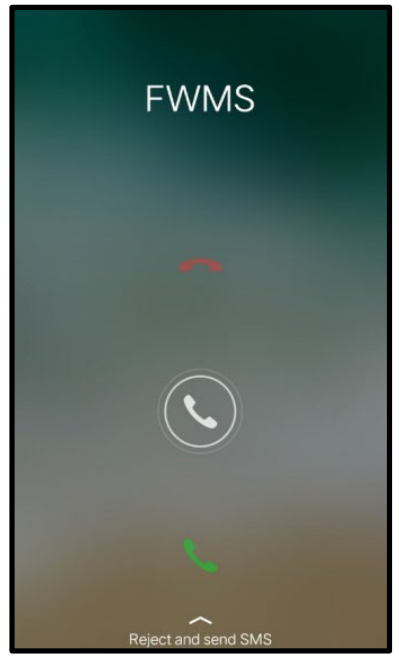

Figure 8: Alarm call from FWMS

FWMS also sends a warning SMS to the Fire and Rescue Department in order to report about the current flood water level status and the rescuers can make an early action to help or rescue the victims accordingly. The SMS is sent to the Fire and Rescue Department as shown in Figure 9 below.

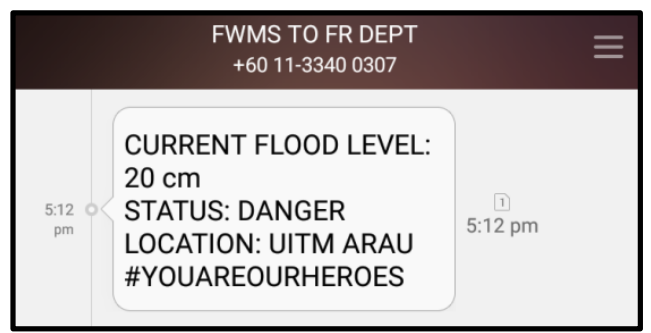

Figure 9: Warning SMS sent to the Fire and Rescue Department

\section{ii. Prototype system test}

The experimentation of the GSM network is obtained by using the same network operator which is Digi operator for both user and the GSM module. Digi network operator is used in the project as the GSM network. This is because Digi operator is one of the best network service providers in Malaysia. Furthermore, Digi provides large area of network service in Perlis. Therefore, this project chose Digi operator as the GSM network. Figure 10 shows the main SMS received by the user when the system has turned on. There are three options that the user can choose in order to control the system: 
a. OFF - Turn off

b. ON - Turn on

c. STATUS - Monitor the real-time flood water level

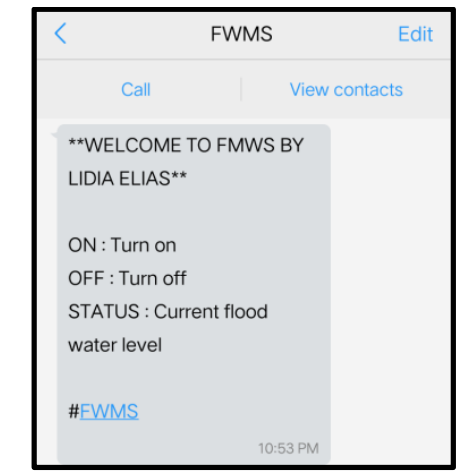

Figure 10: Main menu SMS of FWMS

Table 2 shown below is the result of prototype system test. OFF option is the first option to be tested in this testing case. The testing was conducted at $3.17 \mathrm{pm}$ by using a digital watch to count the response time. The developer sent "OFF" SMS to the prototype system and counted the time taken of the delivery time of the SMS reply. It is roughly estimated that the SMS delivered to the user in three seconds while "ON" option SMS was estimated two seconds for the SMS reply to be received by the user. In addition, "STATUS" option SMS replied the real-time flood water level about three seconds to the user.

Table 2: Result of the Prototype System Test

\begin{tabular}{|c|c|c|c|c|c|c|c|}
\hline \multirow[t]{2}{*}{ Options } & \multicolumn{2}{|c|}{ Time of the SMS } & \multicolumn{4}{|c|}{ Expected Outcomes } & \multirow{2}{*}{$\begin{array}{c}\text { Result } \\
\text { (Qualitative } \\
\text { Method) }\end{array}$} \\
\hline & SMS sent & $\begin{array}{l}\text { SMS } \\
\text { receive }\end{array}$ & $\begin{array}{c}\text { Ultrasonic } \\
\text { Sensor }\end{array}$ & LED & LCD & Buzzer & \\
\hline $\begin{array}{c}\text { Case 1: } \\
\text { OFF }\end{array}$ & $3.17 \mathrm{pm}$ & $3.17 \mathrm{pm}$ & OFF & OFF & $\begin{array}{c}\text { No } \\
\text { Display }\end{array}$ & OFF & 3 seconds \\
\hline $\begin{array}{c}\text { Case 2: } \\
\text { ON }\end{array}$ & $3.18 \mathrm{pm}$ & $3.18 \mathrm{pm}$ & ON & $\mathrm{ON}$ & Display & ON & 2 seconds \\
\hline $\begin{array}{l}\text { Case 3: } \\
\text { STATUS }\end{array}$ & $3.19 \mathrm{pm}$ & $3.19 \mathrm{pm}$ & \multicolumn{4}{|c|}{ Receive real-time flood water level } & 3 seconds \\
\hline
\end{tabular}

Figure 11 and Figure 12 shown below are the successful two-way communication between the user and the system.

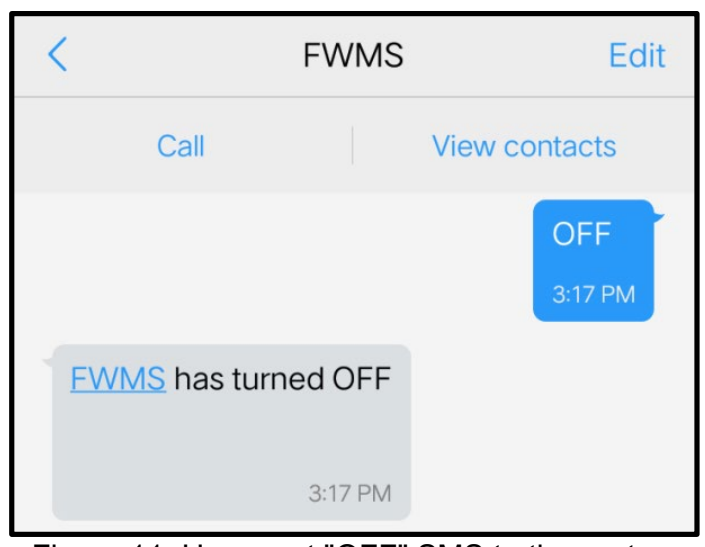

Figure 11: User sent "OFF" SMS to the system 


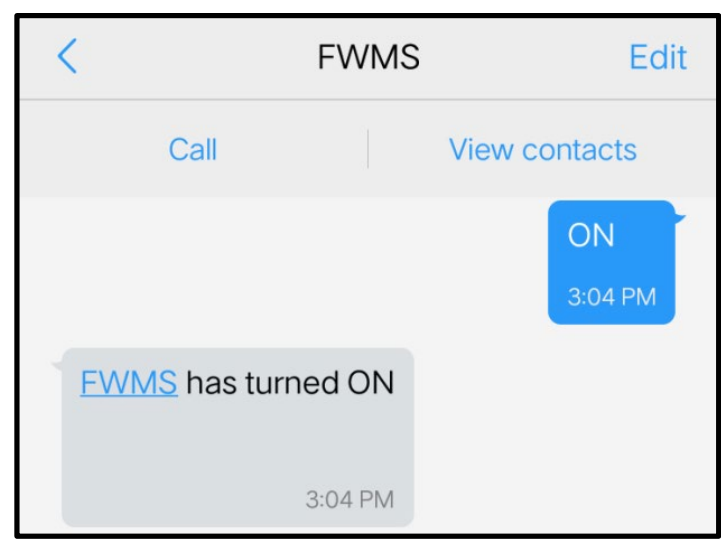

Figure 12: User sent "ON" SMS to the system

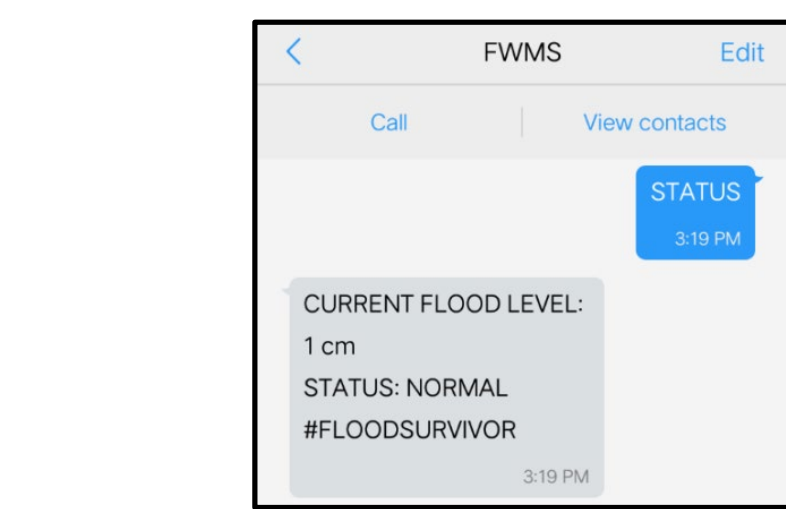

Figure 13: User sent the request SMS to get the current flood water level

Figure 14 shows the result of SMS response time of the system to the user. As for the analysis, the developer has found that the range of the response time of SMS reply from the system to the user is two to three seconds (roughly estimated).

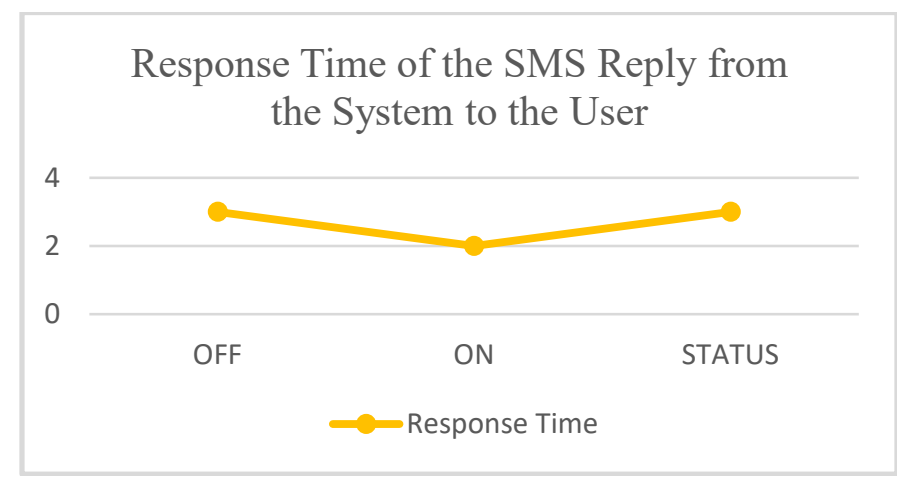

Figure 14: Graph of the response time of the SMS reply from FWMS to the user

\section{iii. GSM Network Performance Test}

The GSM network tests are tested with different locations of the user. Based on the test result tables, the locations are specified with the distances between the user and the prototype location. The two locations that are selected for the prototype experimentation are:

a) Location 1: UiTM Perlis's Dahlia 1 hostel.

b) Location 2: Kampung Padang Malau, Beseri. 
Other than that, there are three response time that are examined and based on the response time of every functions that related to the GSM network. Qualitative method is used. The tested GSM network response times are:

- The delivery time of warning SMS

- Time taken of incoming alarm call

- The delivery time of warning SMS received by the Fire and Rescue Department.

\section{$\underline{\text { Location } 1}$}

There are six cases for GSM network performance test at Dahlia 1 hostel. These cases are differentiated with different locations of user. In order to know if the warning SMS(s) and alarm call are received by the user, the test cases are conducted.

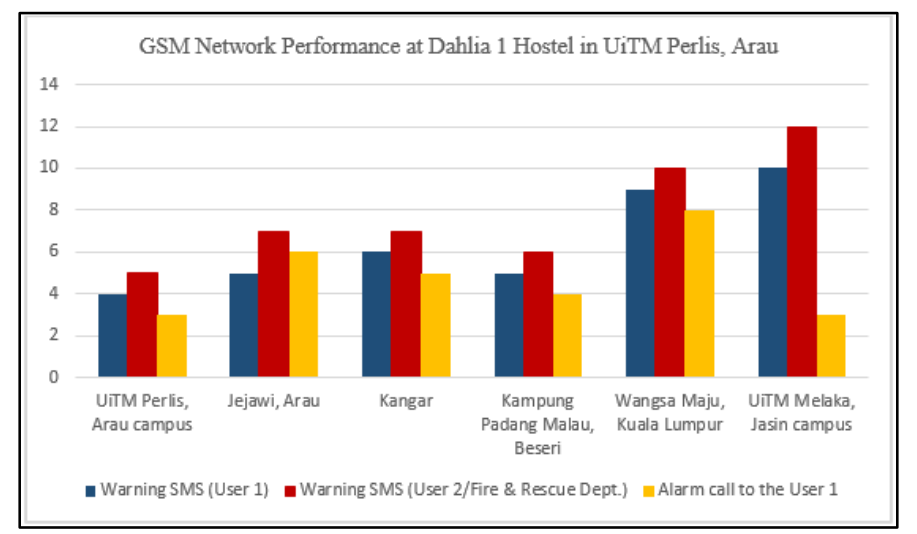

Figure 15: Graph of the GSM network performance from Location 1

The test cases of the GSM network performance show that the response times of the functions are in the range of two to four seconds. The range response time of delivering the warning SMS to the user, is within four to twelve seconds while three to ten seconds for the alarm call.

\section{$\underline{\text { Location } 2}$}

Kampung Padang Malau, Beseri area is one of floodplain area in Perlis. This because the village is located near a river. The river is the main factor that Kampung Padang Malau becomes a flood-prone area.

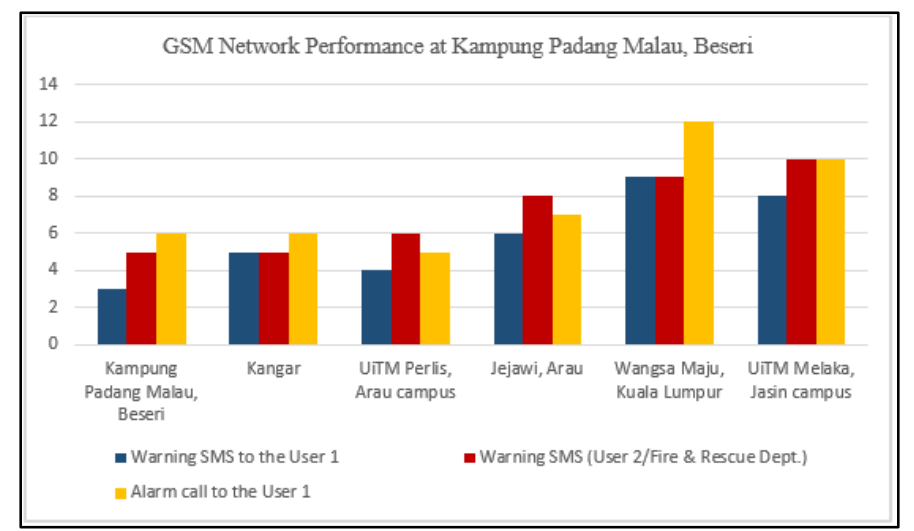

Figure 16: Graph of the GSM network performance from Location 2 
The test cases of the GSM network performance show that the response times of the functions are in the range of two to four seconds. The range response time of delivering the warning SMS to the user, is within two to four seconds. Meanwhile, it takes three to four seconds for the alarm call. These results were conducted by using the qualitative method.

\section{RESULTS AND FINDINGS}

For the first test which is the prototype functionality test, it can be concluded that the ultrasonic sensor reads the distance accurately if the object reflected by the sensor is flat or solid. However, water surface can also be read. The expected outcomes are all successfully met. Therefore, the developed prototype is functioning according to the project requirements.

The complete system test can conclude that the two-way communication between the prototype and the user is successfully performed. This is the crucial test and takes a long time to be solved due to unsuccessful coding test. The two-way function is included in this project to enable the user monitors the flood water level when possible risk of flooding around their area is high. Therefore, the function is successfully made. However, there is a problem when the GSM network could not catch or fetch the SMS request from user. This problem has made the user to send several SMS requests to the prototype until the prototype is successfully replied.

The last test case is the GSM network performance test. It can be concluded that the response time of the warning SMS and alarm call is within three to twelve seconds. However, the observation that has been made found that the distance of the two locations slightly affect the time taken of the response time. Unstable network problem may happen when the area is interrupted by the building structures and/or the network coverage is unavailable. The overall test was successfully made and analysed.

\section{CONCLUSION AND RECOMMENDATIONS}

FWMS has been developed to decrease the rate of property destructions and deaths due to flood disaster. The system is able to call and send warning SMS to the user and Fire and Rescue Department when the flood water level has reached warning and danger levels. This system provides two-way communication system. The user can send a request SMS to monitor the flood water level and control the system by turning on or off the system. It is embedded with a buzzer that will be activated when the flood water level has reached over the warning and danger levels.

For future works, it is highly recommended for the future researchers to add a functional GPS sensor for locating the flood-plain area and inform to the Fire and Rescue Department when the flood water level reaches dangerous level. This is because; the current developed project does not embed with the GPS sensor to locate the location of the system.

Furthermore, the future researchers can also build a simple mobile application for the user to monitor the real-time flood water level easily. The mobile application can include the graph of ultrasonic sensor reading when the flood water level increases and record the date and time of the occurred event.

\section{REFERENCES}

.Bernama. (2017, September 22). Perlis Flood Evacuees Number Nearly 2,400. Malay Mail. Retrieved September 22, 2017, from https://www.malaymail.com/s/1470811/perlis-flood-evacuees-numbernearly-240. 
Chan, N. W. (2012). Impacts of disasters and disaster risk management in Malaysia: The case of floods. In: Sawada, Y., Oum, S., editors. Economic and Welfare Impacts of Disasters in East Asia and Policy Responses. ERIA Research Project Report 2011-8, Jakarta: ERIA. p497-545.

Cherishma, J. S., Adithya, G. Y. S., Krishna, R., Prakasam, S. A. I., Of, G., Ece, I. I. I., ... Of, G. (2017). IoT based floods Alerting system, (March), 41-45.

Department of Irrigation and Drainage. (2013). Pengurusan Banjir - Program dan Aktiviti. Retrieved from http://www.water.gov.my/our-services-mainmenu252/floodmitigation-mainmenu 323/programme-aamp- activities-mainmenu199?lang=my\&showall=1

Diaz, J. H. (2004). The public health impact of hurricane and major flooding. The Journal of the Louisiana State Medical Society, 156(3), 145-150.

Eetha, M. G., Ekhar, K. R. A. J. A. S., Aj, V. D. H. R., \& Ravin, A. P. (2017). IOT based Flood Monitoring System Using LPC2148, 5(5), 916-920. FitzGerald, G., Du, W., Jamal, A., Clark, M., \& Hou, X. Y. (2010). Flood fatalities in contemporary Australia (1997-2008). Emergency Medicine Australasia, 22(2), 180-186.

Jacquier, A. (2015). Sms Based Flood Monitoring and Early Warning System, 10(15), 6387-6391.

Khalid, M. S. Bin, \& Shafiai, S. B. (2015). Flood Disaster Management in Malaysia: An Evaluation of the Effectiveness Flood Delivery System. International Journal of Social Science and Humanity, 5(4), 398-402. https://doi.org/10.7763/IJSSH.2015.V5.488

Priya, S. J., Akshaya, S., Aruna, E., Julie, J. A. M., \& Ranjani, V. (2017). Flood Monitoring and Alerting System, 8(2), 1-5. 